\title{
Cell Population Analysis of Radiation Leukemogenesis in Mice
}

\author{
Chikako Sato \\ Department of Radiation Research (Prof. M. Sakka), \\ Tohoku University School of Medicine, Sendai
}

\begin{abstract}
Young C57BL mice were irradiated with a leukemogenic dose of $\mathbf{x}$-rays in four fractions with an interval of seven days. Differential cell count was carried out in the course of tumor development on the cellular suspension of the thymus or lymph nodes. The normal differentiation of large lymphocytes to small lymphocytes was recognized always after each irradiation. The accumulation of blast cells due to maturation arrest was not seen in the whole period of regeneration. The population of neoplastic cells appeared among normal lymphocytes as early as 14 days after the fourth irradiation. The rate of tumor cell induction at the time of irradiation was $1 \cdot 10^{-4}$ to $1 \cdot 10^{-5} / \mathrm{R}$ in the blasts cells. The population of self-replicating cells increased exponentially with the doubling time of 7.3 days and constituted a large thymoma. In the lymph nodes, numerous foci of unusual proliferation of blast cells without differentiation were observed in the cortex, but further development of the foci was suppressed. The immunological insufficiency in the thymus may be responsible for the development of neoplastic cells in the organ. Extreme lymphopenia for a long period may also be associated with tumor cell development.
\end{abstract}

Since Kaplan and coworkers ${ }^{1}$ established the optimum radiation dose and intervals to induce thymoma in mice, fractionated irradiation has been found to be one of the most effective methods. The changes in the thymus weight and the histological or histochemical findings ${ }^{2-7}$ of the carcinogenic process have been reported, and some interesting hypotheses ${ }^{5,8-11}$ have been proposed from these observations on the mechanisms of thymoma development. But quantitative data are still lacking and the essential nature of the leukemogenic process remains to be elucidated.

In the present experiment, the absolute number of cells of different types was counted at 34 points in the course of thymoma development in the thymus and lymph nodes. Attempt was made to analyze the appearance and proliferation of noeplastic cells from these measurements. Histological examinations were also performed at each point in the course of carcinogenesis to find out the changes in the structure, and the results were compared with the change in cell population.

Received for publication, May 13, 1968. 


\section{Materials and Methods}

Animals and irradiation. C57BL mice had originally been supplied by National Institute of Animal Health and had been reproduced in our laboratory. Three hundred and seventy-seven males and females of $\mathrm{C} 57 \mathrm{BL} / 6$ mice received four doses of $170 \mathrm{R}$ or $260 \mathrm{R}$ wholebody irradiation at intervals of 7 days. Experiments were supplemented with female dd-mice supplied from Central Farm for Experimental Animals, Tohoku University School of Medicine. This colony of mice had been sustained by the brother-sister mating for 24 generations and proved to be free of specific pathogens. Irradiation was started at $32 \pm 3$ days of age at the body weight of $15.5 \pm 1.5 \mathrm{~g}$. The physical factors of irradiation were $180 \mathrm{kVp}, 20 \mathrm{~mA}, 0.5 \mathrm{mmAl}+0.7 \mathrm{mmCu}$ filter, $\mathrm{HVL}=1.22 \mathrm{mmCu}, 40 \mathrm{~cm}$ distance and $83 \mathrm{R} / \mathrm{min}$.

Preparation of cell suspension. ${ }^{12}$ Six to 19 mice were killed and dissected at 34 different times in the course of carcinogenesis. After weighing, the thymus and the lymph nodes (cervical, axillary, brachial and mesenterie nodes) were minced well with scissors and rubbed against the metal mesh (No. 100) with a tip-rounded glass rod to make cell suspensions in physiological saline. The volume of the saline was adjusted to make a concentration of 1 to $6 \times 10^{7}$ cells $/ \mathrm{ml}$. When the thymus was minced well with a sharp scissors and rubbed repeatedly against the metal sieve, more than $95 \%$ of lymphoid cells and more than $80 \%$ of reticulum cells were collected in the cell suspension.

Differential cell count. Four hundred to $\mathbf{2 , 4 0 0}$ cells (in 4 fields) were counted with hemocytometers. The absolute number of cells in an organ was calculated by multipling the value in one field by the dilution factor. Smears were stained with May-GrünwaldGiemsa and differential cell count was carried out on smears and with a hemocytometer for the three cell types; small lymphocytes, medium and large lymphocytes, and reticulum cells. Small lymphocytes had cell diameters of less than $7 \mu$ on smears and $4.5 \mu$ with a hemocytometer. Medium and large lymphocytes (lymphoblasts) were larger than that limit and distinguished from reticulum cells by round basophilic nucleus and welllimited cytoplasm, large nuclear-cytoplasmic ratio and absent phagoeytosis.

Histological examinations. The thymus, lymph nodes and spleen were weighed and fixed in Maximow's solution or in 10\% formalin, embedded in paraffin, sectioned at $4 \mu$ in thickness and stained with May-Crünwald-Giemsa or hematoxylin-eosin.

\section{Results}

\section{1) Mortality and incidence of thymoma}

Animals were observed for 200 days after the first irradiation. The number of mice used and the results are summarized in Table 1. For the calculation of tumor incidence, thymoma was diagnosed when the thymus exceeded $100 \mathrm{mg}$ in weight and contained blast cells in more than $20 \%$ of the total cells. The mice dead or killed before 180 days without any evidence of thymoma were omitted. Severe atrophy of all the lymphoid tissue was already evident at the dissection of moribund or dead mice, and the change was further confirmed by the histological examinations. Hemorrhage in the spleen or infection was found in some cases.

\section{2) Change in the cell population of the thymus after the first irradiation}

The results of C57BL mice after 170R are illustrated in Fig. 1. From 2 to 4 days after the exposure, the number of large and medium lymphocytes in a 
TABLE 1. Mortality and incidence of thymoma

\begin{tabular}{l|c|c|c}
\hline \multicolumn{1}{|c|}{ Strain of mice } & \multicolumn{2}{|c|}{ C57BL } & $\mathrm{dd}$ \\
\hline Dose & $170 \mathrm{R} \times 4$ & $260 \mathrm{R} \times \mathbf{4}$ & $260 \mathrm{R} \times 4$ \\
\hline $\begin{array}{l}\text { Number of mice } \\
\text { Death within 60 days } \\
\text { of the lst exposure }\end{array}$ & 339 & 40 & 320 \\
$\begin{array}{c}\text { Death within 200 } \\
\text { days }\end{array}$ & 32 & 38 & 11 \\
$\begin{array}{l}\text { Mortality } \\
\text { Incidence of thymoma } \\
\text { within 200 days }\end{array}$ & $11.2 \%$ & 40 & 14 \\
$\begin{array}{c}\text { 95\% confidence } \\
\text { interval of the } \\
\text { incidence }\end{array}$ & $83 / 56$ & 0 & $4.4 \%$ \\
\end{tabular}

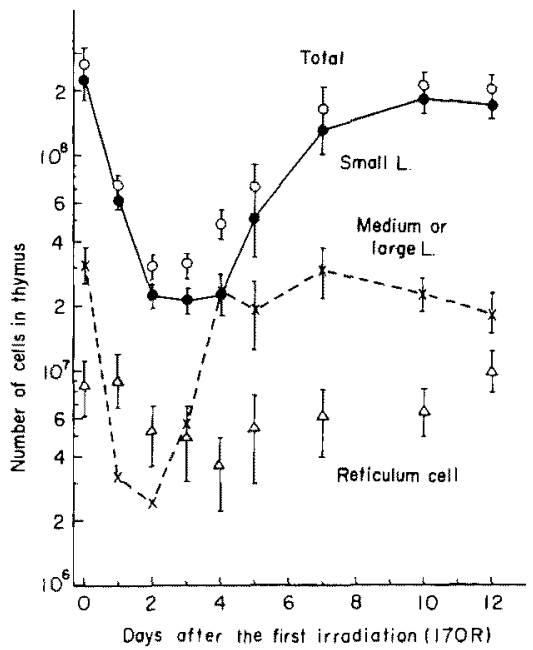

Fig. 1. Change in the number of cells of different types in C57BL mice after the lst irradiation. After the initial depletion of lymphoid cells a two-phase pattern of lymphopoiesis was recognized. The first phase of proliferation of blast cells $(\times)$ was followed by their differentiation into small lymphocytes $(\cdot)$. The number of reticulum cells $(\Delta)$ was almost constant. Vertical lines represent standard deviations for 6 to 10 mice.

thymus increased from $(2.46 \pm 0.4) \times 10^{6}$ to $(2.36 \pm 0.4) \times 10^{7}$ cells. This was a 9.6 fold increase. At this early recovery period the production of small lymphocytes was not recognized. In the next three days the number of large and medium lymphocytes remained at the same level of about $2.2 \times 10^{7}$, whereas the number of small lymphocytes increased linearly by $3.7 \times 10^{7}$ cells every day up to the 8 th day of irradiation. These results revealed a two-phase pattern of lymphopoiesis after irradiation; the first phase of proliferation and the second of differentiation. The first three or four divisions of large or medium lymphocytes were self-replication to yield two parental type daughters, which corresponded to a 9.6 fold increase of 
exponential growth 2 to 4 days after exposure. After four days, however, the division of these cells apparently changed in such a way as to yield one small lymphocyte and one larger cell. It was considered that on account of this asymmetrical division the number of large and medium lymphocytes remained constant and small lymphocytes accumulated arithmetically. The doubling time calculated from the growth curves was 12 hours for the symmetrical division in the first phase and 15 hours for the asymmetrical one in the second. The evidence of regeneration in the two phase was obtained after the single exposure of $260 \mathrm{R}$ or $400 \mathrm{R}$ in the two strains of mice. ${ }^{12}$ The proliferation of large and medium lymphocytes began earlier in dd-mice than in C57BL mice. The degree of regeneration of the thymus 7 days after the exposure was similar in $260 \mathrm{R}$ for dd and in $170 \mathrm{R}$ for $\mathrm{C57BL}$ mice.

\section{3) Change in the number of cells of the thymus after the fourth irradiation}

The number of total cells of the thymus had not regained the control level at the day of the next irradiation. The size of total cell population was only $50 \%$ of the control on the seventh day of the fourth exposure. The response of cell population in C57BL mice is illustrated in Fig. 2. The pattern of regeneration was quite similar to that after the first irradiation as a whole. There were the first phase of blast cell proliferation and the next phase of differentiation into small lymphocytes, which was followed by a secondary drop in the cell number on the 35th day.

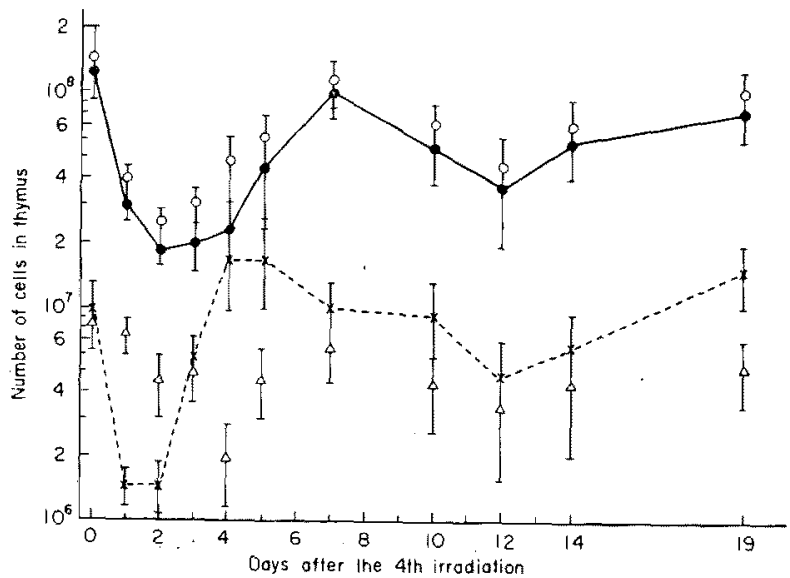

Fig. 2. Change in the cell population of the thymus of C57BL mice after the 4th irradiation. Normal regeneration of blast cell $(x)$ proliferation and sucessive differentiation into small lymphocytes $(\bullet)$ was found but was followed by the secondary lymphoid cell depletion. Vertical lines indicate the standard deviation for 6 to 19 mice.

\section{4) Proportion of large and medium lymphoid cells in the thymus}

The proportion of blast cells in thymic cell suspensions changed with time as indicated in Fig. 3. A remarkable peak appeared 3 to 4 days after each irradia- 


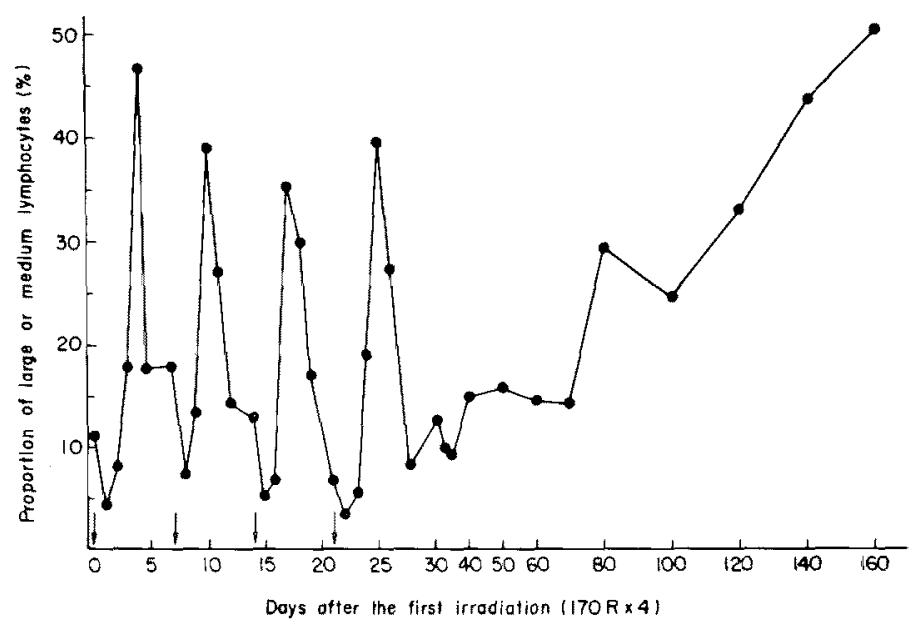

Fig. 3. Time course of the proportion of blast cells in the thymus. A sharp peak and abrupt fall after each irradiation were noted, and maturation arrest in the regenerative period was not indicated. Arrows indicate the time of irradiation.

tion and the normal level was attained on the seventh day of exposure. It is to be noted that the accumulation of blast cells due to the maturation arrest was never observed even after the last irradiation. After 40 days, however, the blast cells increased continuously to about $50 \%$ of the total cells in the thymus.

\section{5) Population kinetics of lymphoid cells of the thymus in leukemogenic process}

All the experimental results are summarized in Fig. 4 for C57BL and in Fig. 5 for dd-mcie. The time course of the number of small lymphocytes showed four repetitions of cell depletion and repopulation. A secondary drop 35 days after the first irradiation was significant. After 50 days the number of small lymphocytes reached the pre-irradiation level and remained almost constant at 1 to $1.5 \times 10^{8}$ cells. On the other hand, the larger lymphoid cells increased unrestrictively from the 35th day up to the death of the animal in which large thymoma was always detected. It suggests that tumor cells induced by irradiation grow consistently among normal lymphocytes. An attempt was made then to separate the neoplastic cells from normal blast cells in a population of medium and large lymphocytes. The size of normal blast cell population was estimated from the following findings: (1) Intrathymic life span of small lymphocytes is about 4 days. ${ }^{15,18}$ Therefore, the population of small lymphocytes loses one-fourth of their number every day. (2) The number of blast cells in the thymus is calculated from the value indicated in Fig. 1 as $12 \%$ of that of small lymphocytes in the normal steady state. (3) Each of normal blast cells divides twice a day and yields two small lymphocytes every day. ${ }^{12}$ This value was estimated from the growth curves in Fig. I as explained in the text:

In general, let the number of small lymphocytes be $n_{1}$ on day $t_{1}$ and $n_{2}$ on day $t_{2}$. The difference between $n_{1}$ and $n_{2}$ is a sum of cell production ( $\left.2 t X\right)$ and cell 


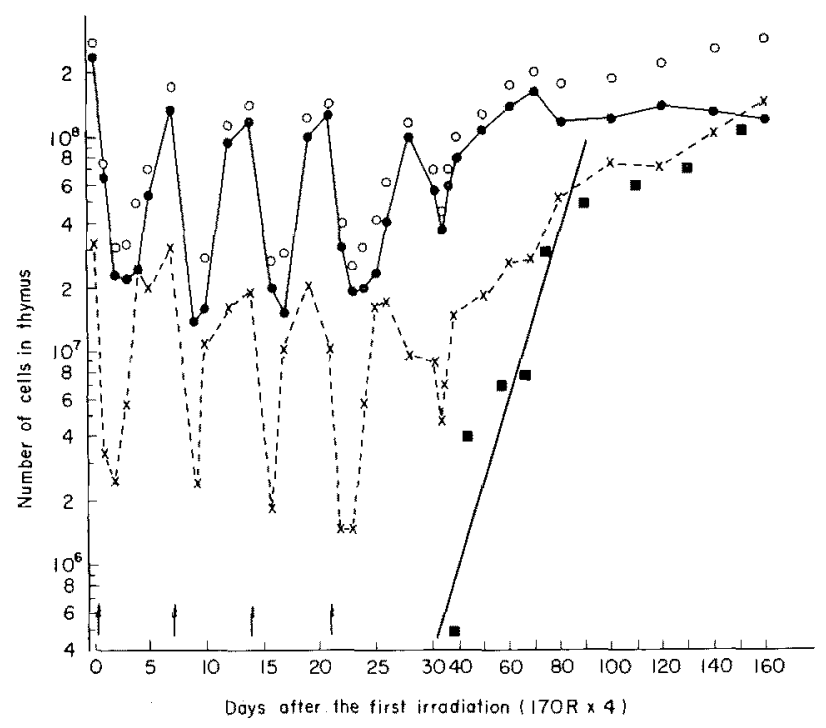

Fig. 4. Changes in the number of total cells $(0)$, small lymphocytes $(\bullet)$, medium and large lymphocytes $(*)$ and neoplastic cells $(\cdot)$ in the thymus of C57BL mice. Each point represents the average of 6 to 19 mice. The method of the calculation of neoplastic cells and the regression line are described in the text.

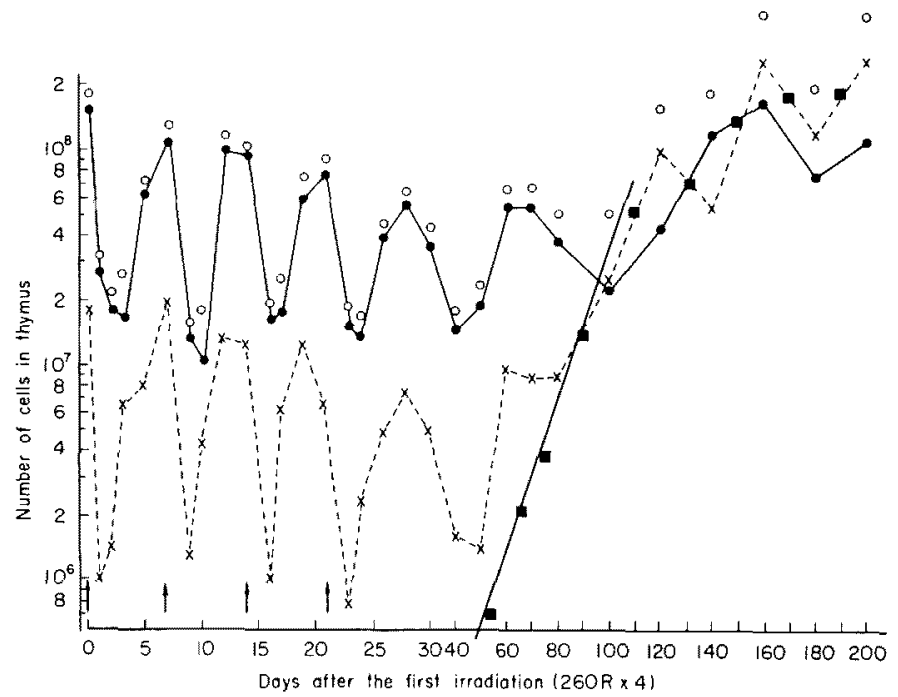

Fig. 5. Change in the number of total cells (o), small lymphocytes (•), medium and large lymphocytes $(\times)$ and neoplastic cells $(\cdot)$ in the thymus of dd-mice. Six to 11 mice were used for each determination.

loss $\left(-\frac{n_{1}+n_{2}}{2} \times \frac{t}{4}\right)$, where $t$ is the time interval between $t_{1}$ and $t_{2}$, and $X$ is the number of normal lymphoblasts at the midpoint of $t_{1}$ and $t_{2}$. When a linear behavior is assumed in lymphoid cell population in a short time, the number of normal blast cells will be expressed as follows; 


$$
X=\frac{1}{2 t}\left(n_{2}-n_{1}+\frac{n_{1}+n_{2}}{2} \times \frac{t}{4}\right)
$$

The size of neoplastic cell population was estimated by the subtraction of $X$ from the total number of medium and large lymphocytes. Relevant values are listed in Table 2 and the number of neoplastic cells is illustrated in Figs. 5 and 6 as solid square. The following regression line was obtained by the method of least squares for C57BL mice,

$$
\log Y=0.0398 X+4.42
$$

where $Y$ is the number of neoplastic cells at day $X$ after the first irradiation. The differences between observed and expected values were tested by the $\chi^{2}$ method at $5 \%$ level for the day 35 to 100 . The calculated value, $\chi^{2}=8.98$, with a degree

TABLE 2. Calculation of the population of neoplastic cells in thymus

\begin{tabular}{c|c|c|c|c}
\hline $\begin{array}{c}\text { Days after lst } \\
\text { exposure } \\
t_{1}-t_{2}\end{array}$ & $\begin{array}{c}\text { Small } \\
\text { lymphocytes } \\
\left(n_{1}\right)\end{array}$ & $\begin{array}{c}\text { Medium and } \\
\text { large } \\
\text { lymphocytes }\end{array}$ & $\begin{array}{c}\text { Normal blast } \\
\text { cells } \\
(X)\end{array}$ & $\begin{array}{c}\text { Neoplastic } \\
\text { cells }\end{array}$ \\
\hline $35-40$ & $5.79 \times 10^{7}$ & $1.077 \times 10^{7}$ & $1.03 \times 10^{7}$ & $4.7 \times 10^{5}$ \\
$40-50$ & 7.67 & 1.64 & 1.26 & $3.8 \times 10^{6}$ \\
$50-60$ & 10.5 & 2.32 & 1.65 & $6.7 \times 10^{6}$ \\
$60-70$ & 13.4 & 2.66 & 1.94 & $7.2 \times 10^{6}$ \\
$70-80$ & 15.7 & 4.42 & 1.46 & $2.96 \times 10^{7}$ \\
$80-100$ & 11.2 & 6.15 & 1.33 & $4.82 \times 10^{7}$ \\
$100-120$ & 11.8 & 7.13 & 1.59 & $5.54 \times 10^{7}$ \\
$120-140$ & 13.1 & 8.46 & 1.60 & $6.87 \times 10^{7}$ \\
$140-160$ & 12.6 & 11.75 & 1.48 & $1.03 \times 10^{8}$ \\
\end{tabular}

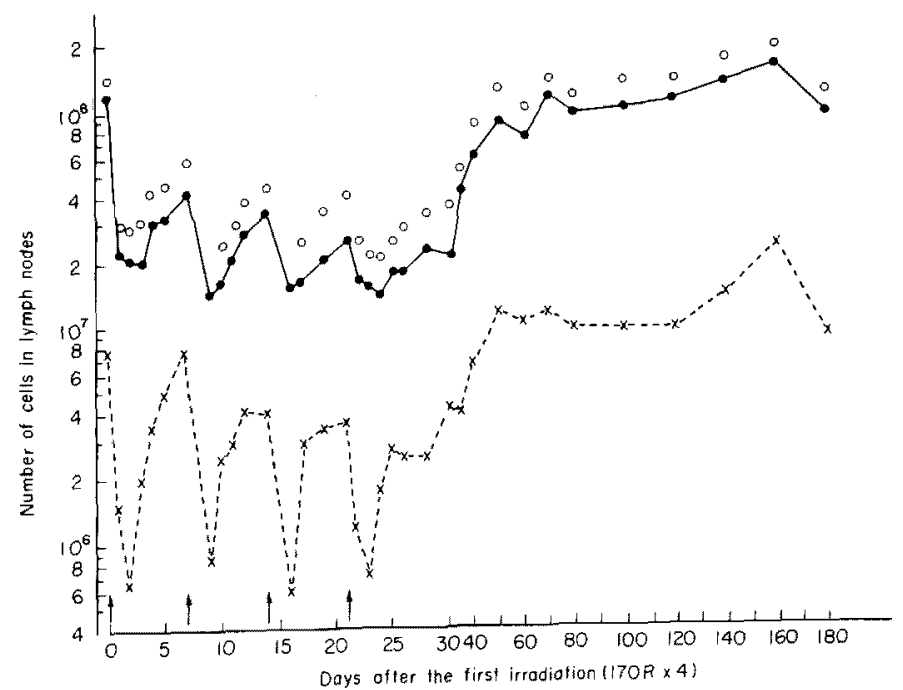

Fig. 6. Change in the number of total cells (o), small lymphocytes (•), medium and large lymphocytes $(x)$ in the lymph nodes (sum of cervical, axillary, brachial and mesenteric nodes) of $\mathrm{C} 57 \mathrm{BL}$ mice. 
of freedom of 5 , indicated an exponential growth of neoplastic cells with the doubling time of 7.3 days. By extrapolating this line, tumor cells at the time of the fourth irradiation was estimated at $1.78 \times 10^{5}$. The number of target cells (medium and large lymphocytes) was $3.14 \times 10^{7}, 3.08 \times 10^{7}, 1.87 \times 10^{7}$ and $1.10 \times 10^{7}$ at the 1st, 2 nd, $3 \mathrm{rd}$ and 4 th irradiation, respectively. If all the tumor cells induced at the early fraction of four irradiations are to be killed by subsequent exposures, the induction rate of neoplastic cells will be as follows;

$$
\frac{1.78 \times 10^{5}}{1.01 \times 10 \times 170 R^{-}}=1.04 \times 10^{-4} / R \quad \text { (maximum estimation). }
$$

If the tumor cells induced at each irradiation remain intact without loss and reproduction until the last exposure, the rate of induction will be

$$
\frac{1.78 \times 10^{5}}{(3.14+3.08+1.87+1.01) \times 10^{7} \times 170 R}=1.15 \times 10^{-5} / R
$$

(minimum estimation).

The number of tumor cells were calculated in the same way for dd-mice and plotted in Fig. 5 as solid squares. The equation of the regression was obtained as follows;

$$
\log Y=0.0352 X+4.10
$$

where $Y$ is the number of tumor cells at the day $X$ after the first irradiation. The doubling time of the neoplastic cells was 9.1 days.

\section{6) Change in the cell population of lymph nodes in leukemogenic process}

For the simplicity of explanation the results on the number of lymphoid cells in the lymph nodes are summarized in Fig. 6. Repopulation was remarkably retarded in the lymph nodes than in the thymus. Seven days after the first exposure the total number of cells did not exceed $41 \%$ of the pre-irradiation level. Subsequent to the long period of cell depletion, the lymphoid cell population increased and reached the normal level in 50 days, after which the number of total cells remained constant. After 140 days, however, metastasis to all lymph nodes was observed in some animals, reflecting an abrupt increase in the number of larger lymphocytes.

The time course of the proportion of lymphoblasts in the total cells is illustrated in Fig. 7. In contrast with the curve of the thymus, the proportion was still higher than the normal level 7 days after each irradiation and reduced by the next irradiation. After the day 30, the blast cell component remained at a higher level than normal and a peak was found at the day 60 . A considerable number of plasma cells were also observed in this period.

\section{7) Histological examinations on the thymus}

The lymphocyte depletion and following repopulation was found after each irradiation, Histological appearance of the thymus was identical with that of the 


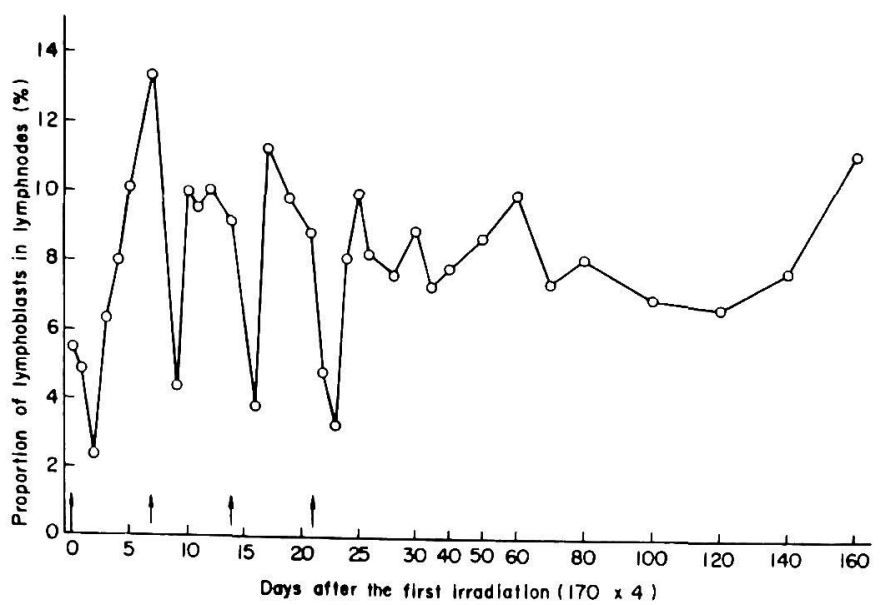

Fig. 7. Proportion of blast cells in the lymph nodes after irradiation.

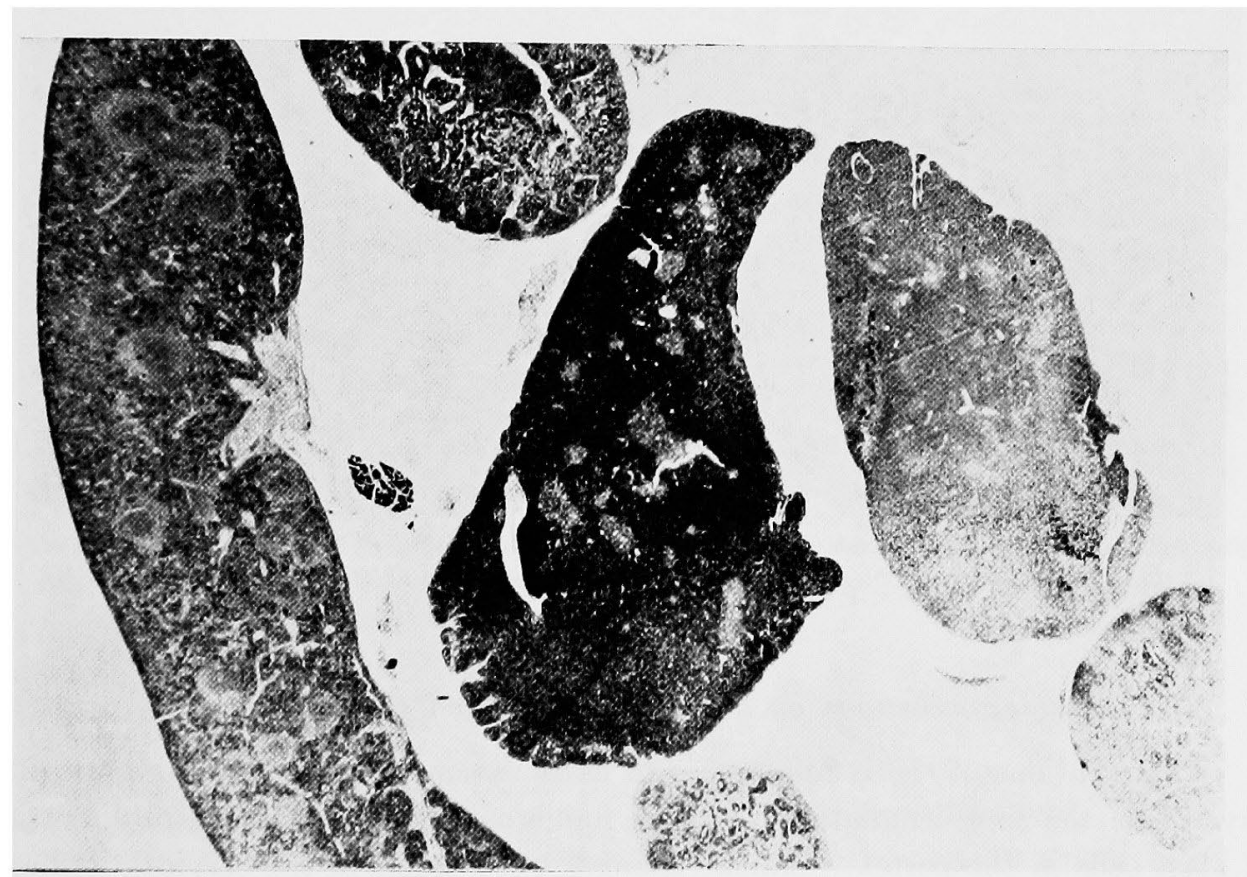

Fig. 8. The right is a small contracted thymic lobe, which is devoid of small lymphocytes and filled with reticulum cells and blast cells of high mitotic activity. The left lobe has a normal structure in the gross.

non-irradiated one on the 8th day of exposure. Detailed examination on early thymic lymphoma revealed two conditions of neoplastic changes in the thymus. In one of them a thymic lobe was small, contracted and devoid of small lymphocytes but abundant in reticulum cells and lymphoblasts of a very high mitotic activity. In this case the other lobe had usually a normal structure (Fig. 8). The other neoplastic condition was characterized by a marked accumulation of blast cells in 
peripheral cortical layer. Mitotic figures were abundant among them. They invaded normal parts of the lobe where well differentiated lymphocytes were present (Fig. 9).

Siegler ${ }^{5}$ reported only the first pattern of unilateral tumor cell evolution in the small contracted thymic lobe. But the neoplastic cells and differentiated small lymphocytes were frequently found together in the same thymic lobe.

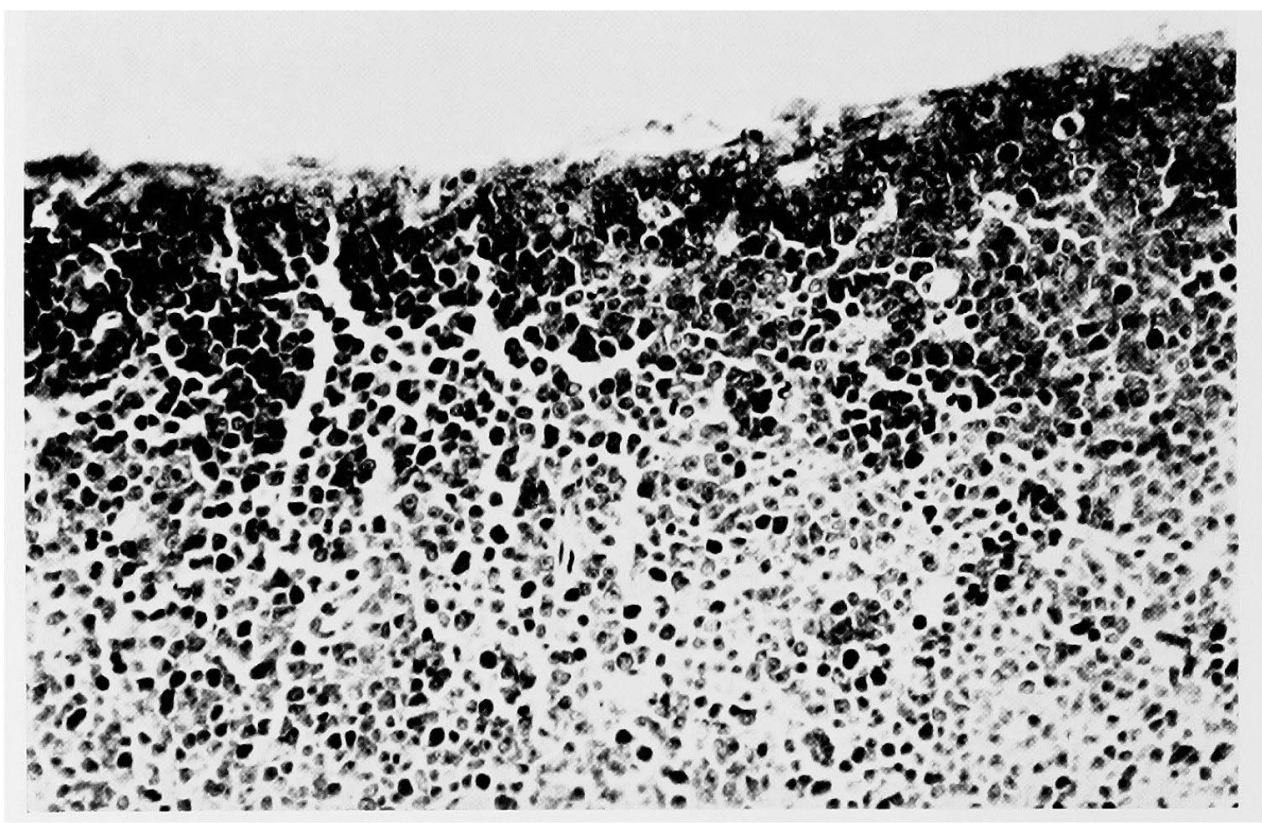

Fig. 9. Accumulation of blast cells in peripheral cortical layer of the thymus with a very high mitotic index. These cells invade the normal part of the lobe.

\section{8) Histological examinations on the lymph nodes and the spleen}

Examinations of the lymph nodes in early carcinogenic period from 40 to 80 days after the first irradiation revealed numerous foci of unusual proliferation of blast cells in the cortex. Similar changes were found in the cervical, axillary, brachial and mesenteric lymph nodes. The mass of blast cells was also found in the lymphoid follicles of the spleen. The blast cell focus was different in appearance from the normal lymphoid follicles. The former consisted of large blast cells with basophilic cytoplasm and large nucleus, and reticulum cells with cell debris. Small lymphocytes were not recognized around the foci (Fig. 10). It suggests a monotonous proliferation of blast (or neoplastic) cells without differentiation to small lymphocytes. The blast cell foci in the lymph nodes appeared in almost all animals, but they did not develop rapidly and unrestrictively. Considerable accumulation of plasma cells was observed around the blast cell focus, 


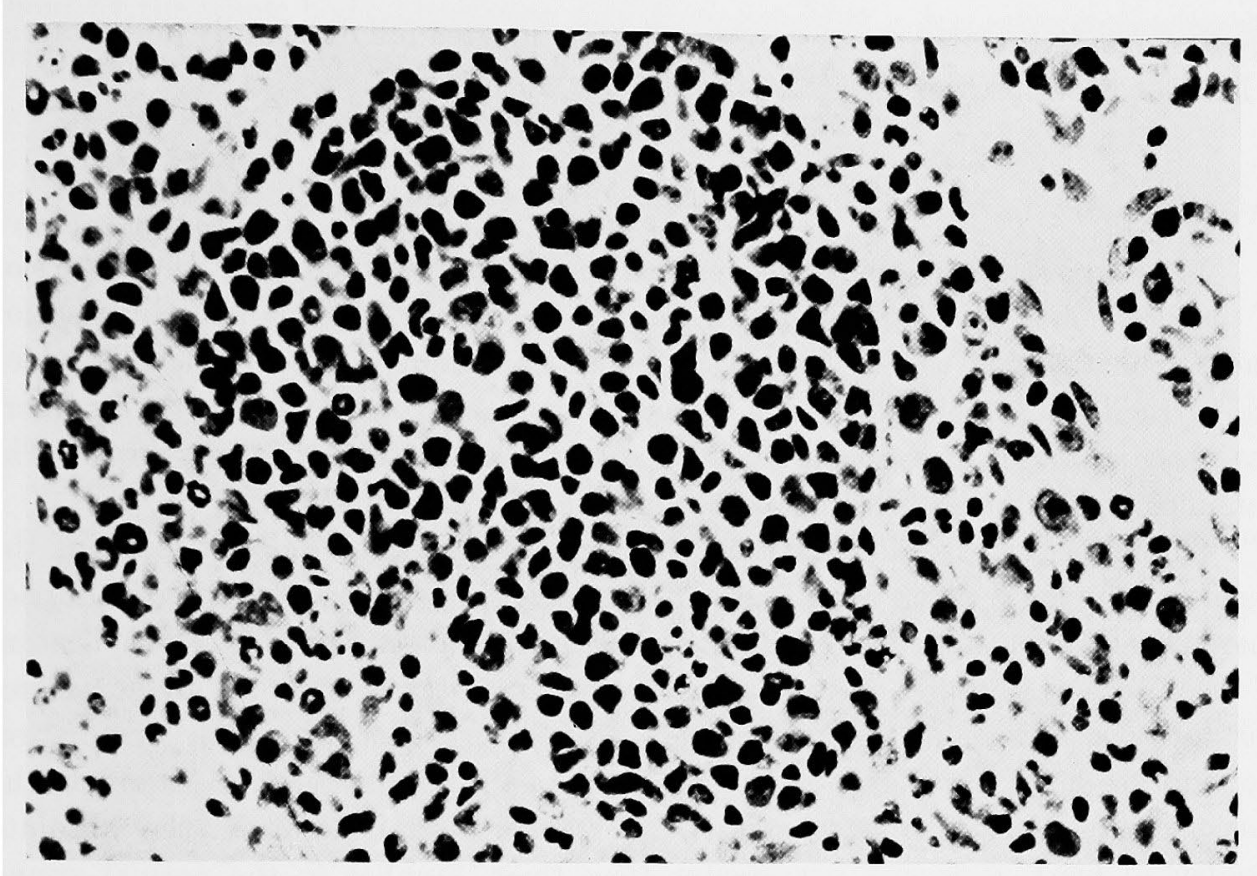

Fig. 10. Focus of large lymphoid cells and reticulum cells in the cortex of a lymph node. It does not contain differentiated small lymphocytes. Many mitotic figures are seen.

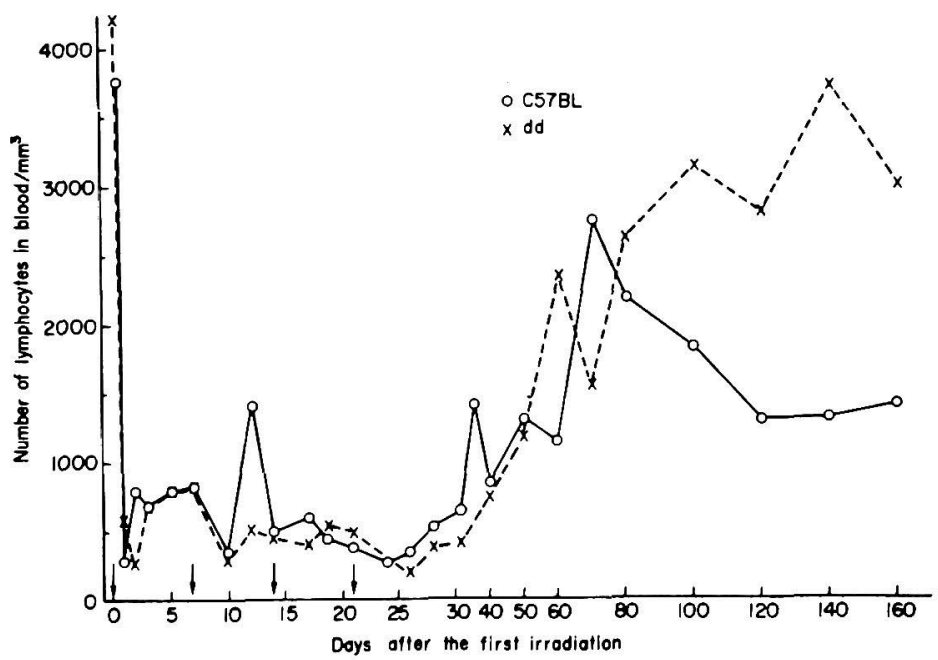

Fig. 11. Change in the number of small lymphocytes in the blood of the caval vein.

\section{9) Change in the number of lymphocytes in the blood}

The number of small lymphocytes in the blood from the inferior caval vein was counted with a hemocytometer. The results are illustrated in Fig. 11. After 
the first irradiation, the number of small lymphocytes fell drastically and retained a level of one-fourth of the normal value for 40 days.

\section{Discussion}

Many investigators acknowledge viral and cellular principles in the induction of murine leukemia. According to Kaplan's hypothesis, ${ }^{11}$ whole body irradiation leads to maturation arrest with a subsequent accumulation of blast cells which are particularly susceptible to the leukemogenic action of the virus. So far, there has been no direct experimental evidence of the activation of latent virus. The immunological impairment might account for the virus infection.

This experiment indicated that the maturation arrest did not exist in the regeneration phase after irradiation. When the two-phased pattern of lymphopoiesis was found after the first irradiation, the duration of the self-replication of blast cells of the first phase by maturation arrest was assumed to be an important mechanism in carcinogenesis. But even after the 4th irradiation medium or large lymphocytes matured to small lymphocytes. Although the porportion of blast cells was highest 3 to 4 days after irradiation, the absolute number of blast cells was not greater than their number in the normal young thymus.

A population of tumor cells was detected in the thymus as early as 35 days after the first irradiation. The neoplastic cells increased exponentially with time among the normal lymphoid cells in the thymus. The doubling time of 7.3 days was far longer than the generation time of lymphoma cells. ${ }^{15}$ Abortive malignant transformation or a selection mechanism might account for it.

In the lymph nodes an increase in both the absolute number and the proportion of blast cells was indicated. Histological examination on lymph nodes also revealed the presence of blast cell foci. These blast cells, however, did not increase unrestrictively. Primary lymphoma of the lymph nodes without thymoma was found only in $2 \%$ of animals with evident thymoma. This extreme difference in tumor development will be attributed partly to the deficiency in the number of blast cells in the lymph nodes and partly to deficient immune responses in the thymus. It is known that the ability of antibody production is greater in lymphocytes of lymph nodes than those of the thymus. The striking reduction in tumor evolution by the injection of bone marrow cells or by bone marrow shielding may also be related to the recovery of immune response. ${ }^{13,14,16}$

The mechanism of malignant transformation of the cells, that is, the first essential step of carcinogenesis is still unknown. But the combined study of cell population kinetics and the histological examination facilitated an approach to the analysis of tumor development. The control mechanisms of lymphocyte differentiation was not affected as a whole at the phase of regeneration. But selfreplicating cells were induced and proliferated unrestrictively among normal lymphoid cells to constitute thymoma. The immunological insufficiency brought 
about by the whole body irradiation may have provided a favorable environment ${ }^{17}$ for the development of tumor cells.

\section{Acknowledgment}

I wish to express my thanks to Prof. T. Mori and Dr. T. Fukuda for their advices on the histological examinations, and to Dr. T. Ino for the supply of C57BL mice.

\section{References}

1) Kaplan, H.S. \& Brown, M.B. A quantitative dose-response study of lymphoid tumor development in irradiated $\mathrm{C} 57$ black mice. J. nat. Cancer Inst., 1952, 13, 185-208.

2) Carnes, W.\& Kaplan, H.S. Histogenesis of lymphomas in irradiated C57BL rice bearing non-irradiated thymic grafts. Proc. Amer. Ass. Cancer Res., 1956, 2, 99.

3) Kaplan, H.S. Early microscopic diagnosis of lymphosarcoma in situ in thymus of irradiated mice. Fed. Proc., 1960, 19, 399.

4) Wasi, P. \& Block, M. The histopathologic study of the development of the irradiation-induced leukemia in C57BL mice and of its inhibition by testosterone. Cancer Res., 1961, 21, 463-473.

5) Siegler, R., Harrell, W. \&ich, M.A. Pathogenesis of radiation-induced thymic lymphoma in mice. J. not. Cancer Inst., 1966, 37, 105-121.

6) Weymouth, P., Delfel, N.E., Doell, R.J., Steinbock, H.L. \& Kaplan, H.S. Nucleic acid content of the thymic cells of normal and irradiated C57BL mice. J. nat. Cancer Inst., 1955, 15, 981-990.

7) Smith, C. Studies on the thymus of the mammal. XIII. Histochemistry of irradiated thymus on C57BL strain mice. J. nat. Cancer Inst., 1962, 29, 375-387.

8) Kaplan, H.S. The role of radiation on experimental leukemogenesis. Nat. Cancer Inst. Monogragh, 1964, 14, 207-220.

9) Latarget, R. Possible mechanisms of radiation-induced malignancy at the cellular level. In: Cellular Control Mechanisms and Cancer, edited by P. Emmelot \& $O$. Muhlbock, Elsevier Publishing Company, Amsterdam, 1964, p. 322.

10) Duplan, J.F. \& Latarjet, R. Studies on the mechanism of radiation-induced leukemogenesis in C57BL mice. Cancer Res., 1966, 26, 395-399.

11) Kaplan, H.S. The role of cell differentiation as a determinant of susceptibility to virus carcinogenesis. Cancer Res., 1961, 21, 981-983.

12) Sato, C. Changes in cell population of thymus, lymph nodes and blood after $\mathrm{x}$ irradiation. Nippon Acta Radiol. (Jap.), 1968, 27, 1529-1536.

13) Kaplan, H.S., Brown, M.B. \& Paull, J. Influence of bone-marrow injections on involution and neoplasia of mouse thymus after systemic irradiation. J. nat. Cancer Inst., 1953, 14, 303-316.

14) Kaplan, H.S. \& Brown, M.B. Further observations on inhibition of lymphoid tumor development by shielding and partial body irradiation of mice. I. nat. Cancer Inst., $1951,12,427436$.

15) Metcalf, D. \& Wiadrowski, M. Autoradiographic analysis of lymphocyte prolifera. tion in the thymus and in thymic lymphoma tissue. Cancer Res., 1966, 26, 483-491.

16) Lorenz, E., Congdon, C.C. \& Uphoff, D. Prevention of irradiation-induced lymphoid tumors in C57BL mice by spleen protection. J. nat. Cancer Inst., 1953, 14, 291-299.

17) Joneja, M.G. \& Stich, H.F. The survival of abnormal cells in the thymus of mice. Exp. Cell Res., 1963, 31, 220-223.

18) Craddock, C.G., Nakai, G.S., Fukuta, H. \& Vanslager, L.M. Proliferative activity of the lymphatic tissues of rats as studied with tritium-labeled thymidine. J. exp. Med., $1966,120,389-412$. 